\title{
Metaphoric Political Insults and Humor: Cognitive Analysis
}

\author{
Alla Martynyuk \\ V.N. Karazin Kharkiv National University, Kharkiv, Ukraine
}

\begin{abstract}
The paper studies cognitive nature of the humorous effects of metaphoric political phrase insults on methodological basis of Conceptual Blending Theory. The analysis shows that humorous effects of such political insults cannot be explained by incongruity resolution-the idea underpinning most cognitive theories of humor. It also proves that their humorous effects can be revealed through backward projection—a highly contextualized cognitive process presupposing re-evaluation of incompatible structure against the background of wide encyclopaedic knowledge “affected” by the blending—ontological, ethological, lingua-ethological, and lingual. Appreciating a metaphoric political phrase insult involves: (1) ontological knowledge-effective insults highlight specific features of the referent incompatible with being a political leader; (2) ethological knowledge—effective insults do not violate ethic norms, avoiding vulnerable social or personal issues; (3) lingua-ethological knowledge - they do not violate norms of communicative behavior, avoiding direct verbal aggression; and (4) lingual knowledge- they do not violate language norms.
\end{abstract}

Keywords: metaphor, political insult, conceptual blending, backward projection, humorous effect

\section{Introduction}

In Western tradition an effective political insult is a powerful means of ruining the image of a political opponent by making the voting audience laugh.

Quite a number of political insults of all times are expressed by phrase metaphors:

[Paul Keating (born 1944), Prime Minister of Australia (1991-96), on John Howard, then leader of the opposition]... a little desiccated coconut.

[The Times, a British newspaper, on Anthony Charles Lynton Blair (born 1953), Prime Minister of the United Kingdom (1997-2007)]... a US poodle.

[Winston Leonard Spencer-Churchill (1874-1965), Prime Minister of the United Kingdom (1951-1955), on Ramsay MacDonald (1866-1937), Prime Minister of the United Kingdom (1929-35)] ... a boneless wonder.

[Michael Foot (1913-2010), British politician, on Norman Tebbit (born 1931), British politician]... a semi-house-trained polecat.

[Gore Vidal (born 1925), American writer and journalist, on Ronald Reagan (1911-2004), President of the United States (1981-89)]... a triumph of the embalmers art.

[Paul Keating (born 1944), Prime Minister of Australia (1991-96), on his opponent]... all tip and no iceberg.

The author's claim is that humorous effects of such metaphoric political insults cannot be explained by incongruity resolution - the idea underpinning most cognitive theories of humor (Koestler, 1964; Minsky, 1980;

Alla Martynyuk, full professor, Ph.D., English Translation Department, V.N. Karazin Kharkiv National University. 
Attardo \& Raskin, 1991).

Firstly, phrase metaphors are not subject to linear processing in the way utterance jokes are: There is no punch line and no violation of expectations.

Secondly, as becomes clear from Blending Theory (Fauconnier \& Turner, 2002), metaphoric blends based on double-scope networks generally involve clashes of incompatible structure from the input spaces, but such incongruity in metaphoric blends does not necessarily make them funny.

\section{Analysis: Mappings and Inferences}

Blending Theory attempts to account for the dynamic aspects of meaning construction. The mechanism of meaning construction is described in terms of integration networks viewed as multiple-space mental lattices. Conceptual units of integration networks are regarded as mental spaces, not domains (as in Conceptual Metaphor Theory) to accentuate the difference in their nature: Domains of knowledge are relatively stable pre-existing knowledge structures, while mental spaces are temporary structures created during the on-line process of meaning construction.

An integration network consists of at least four metal spaces. It has two or more input spaces, a generic space, and also a blending space or blend.

The generic space provides information that is abstract enough to be common to both (or all) the inputs. Elements in the generic space are mapped onto counterparts in each of the input spaces. Counterparts are found by matching. Connectors between matched elements are established in the process of conceptual projection on the basis of identity or role or on the basis of metaphor.

The blend takes elements from both (all) inputs but goes further in providing new-emergent structure - that does not exist in either of the inputs. Not all but only the matched structure from the inputs, which is required for purposes of local understanding, is projected to the blend, so this kind of mapping is called selective projection.

There are three component processes that give rise to emergent structure: (1) composition of elements from the separate input spaces as in the given below example of the SURGEON as BUTCHER blend where elements projected from the SURGEON input are composed with those projected from the BUTCHER input; (2) completion which involves schema induction, that is unconscious and effortless recruitment of background frames to "fill out" or complete the information projected from the inputs in order to derive the blend; and (3) elaboration which is the on-line processing that produces the structure unique to the blend.

Mappings of metaphoric political insults are based on double-scope networks, in which both inputs contain distinct frames and the blend is organized by structure taken from each frame. One consequence of this is that the blend can sometimes include structure from inputs that is incompatible and therefore clashes.

This incompatibility triggers backward projection —a highly contextualized cognitive process in which the structure that emerges in the blend is projected back to the input spaces and undergoes modification as a result of its re-evaluation against the background of wide encyclopaedic knowledge "affected" by the blending. This novel information contributes to the encyclopaedic knowledge system of the addressee. So integration networks of this kind are highly innovative and can lead to novel inferences (for detailed explanation of Conceptual Blending Theory, see Evans \& Green, 2006, pp. 400-440).

Figure 1 represents the SURGEON as BUTCHER blend which is based on a double-scope network in which both inputs contain distinct frames but the blend is organized by structure taken from each frame. One 
consequence of this is that the blend can include structure from inputs that is incompatible and therefore clashes. It is this aspect of double-scope networks that brings about novel inferences.

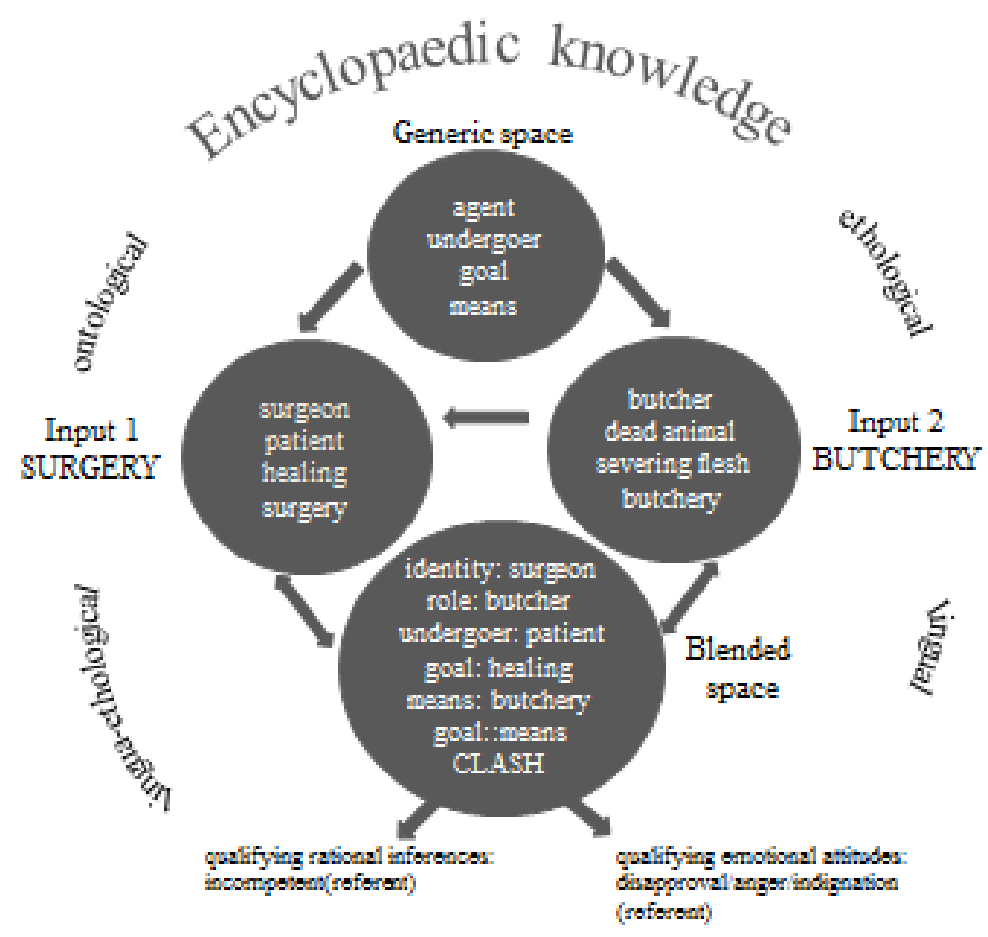

Figure 1. SURGEON as BUTCHER blend.

In the SURGEON as BUTCHER blend the blended space takes elements from both input spaces, but goes further in providing additional (emergent) structure that distinguishes the blend from either of its inputs. In both input spaces there are skilled professionals working in different fields—surgery and butchery. In the blend there is a negatively assessed professional.

This negative assessment results from re-evaluation of the incompatible structures in the blend against the background of wide encyclopaedic knowledge: Goals of surgery cannot be achieved with the means of butchery, so a surgeon who brings inappropriate means to the task at hand is assessed as incompetent. The inference of incompetence arises due to the incompatibility between the attributes goal (healing) and means (butchery) drawn from different inputs. Even though the "ingredients" for the inference are provided by the input spaces it is a derived/emergent structure introducing a novel meaning.

The SURGEON as BUTCHER metaphoric blend is built on incongruity, but this incongruity does not produce any humorous effect. Neither does incongruity explain why some political insults like Paul Keating's metaphoric description of John Howard as a little desiccated coconut are listed among the most funny and effective political put-downs, while others, like calling Canadian Liberal leader Dalton McGuinty an evil reptilian kitten-eater from another planet by an Ontario Tory staff member, cause political scandals and harm the insulter more than the insultee.

The present analysis shows that humorous effects of metaphoric political insults can be explained within the framework of backward projection (Fauconnier \& Turner, 2002, p. 333) presupposing re-evaluation of incompatible structure against the background of wide encyclopaedic knowledge "affected" by the blending —ontological, ethological, lingua-ethological, and lingual. 
The process of backward projection gives rise to a range of novel meanings:

(1) Qualifying rational inferences based on rational assessment of the attributes of the referents of metaphoric political insults, on the one hand, and the insulters, on the other hand, against the background of: (a) ontological knowledge - whether the attributes are realistic enough to highlight the qualities of the referent incompatible with the role of a political leader/the speaker is being precise enough in picking up the qualities of the referent to be highlighted; (b) ethological knowledge-whether the negative social impact the referent's attributes produce still makes it possible for the interpreter to switch from the serious mode to the joking mode/the speaker does not violate ethic norms, avoiding vulnerable social or personal issues; (c) lingua-ethological knowledge - whether the speaker does not violate the norms of communicative behavior avoiding direct aggression using swear words or gestures; and (d) lingual knowledge-whether the speaker does not violate lingual norms.

(2) Qualifying emotional attitudes based on emotional assessment of the referents, evoked by vivid negative images of metaphoric insults, and, consequently, the speakers' general efficiency/inefficiency in choosing the relevant image. In case of the speaker's failure to choose the relevant image this emotional assessment can result in some negative emotional attitude to the speaker (disapproval/anger/indignation, etc.) as violator of (lingua)-ethological norms. In the opposite case an effective image can evoke some condescending feeling to the referent allowing the interpreter to switch to the joking mode where violating norms is just a game;

(3) Behavioral reactions in the shape of: (a) rational inferences as to the relevant patterns of social behavior to respond to the social impact metaphoric insults produce (in the long run, these behavioral inferences influence electoral choices of the interpreters as voters) and (b) emotional patterns of behavior including laughter.

In the case of the SURGEON as BUTCHER metaphor an obvious rational inference is that an incompetent surgeon can harm or kill the patient. This possibility is too realistic and ethically unacceptable for the interpreter to switch to the joking mode. Thus this metaphor can evoke such emotional attitude to the referent as contempt/anger/fear but it can hardly make anybody laugh. Since the speaker is unknown it does not evoke any attitude to the speaker.

The difference between the butcher type metaphor and any effective political metaphoric insult is that the latter is highly contextualized: It brings into focus of attention some specific referent and specific insulter. It means that the interpreter draws information not only from the input spaces covering abstract domains of ontological human experience clashing in the blend (like butchery and surgery), but also from "specific" mental space (by analogy with generic mental space) which stores information about historical and cultural context embedding the referent (and the speaker), their genealogy, education, appearance, traits of character, actions, relations, important events of their life including the event of the insult. All this information will influence the interpretation of and the reaction to a political metaphoric insult.

Figure 2 represents the coconut metaphor based on a multiple-scope network. Its blended space takes elements from the three input spaces.

The three inputs are related by virtue of the generic space, which contains the generic roles ENTITY (OBJECT/HUMAN BEING), ATTRIBUTE. The generic space establishes cross-space counterparts on the basis of identity (value)/role and metaphoric relations. 


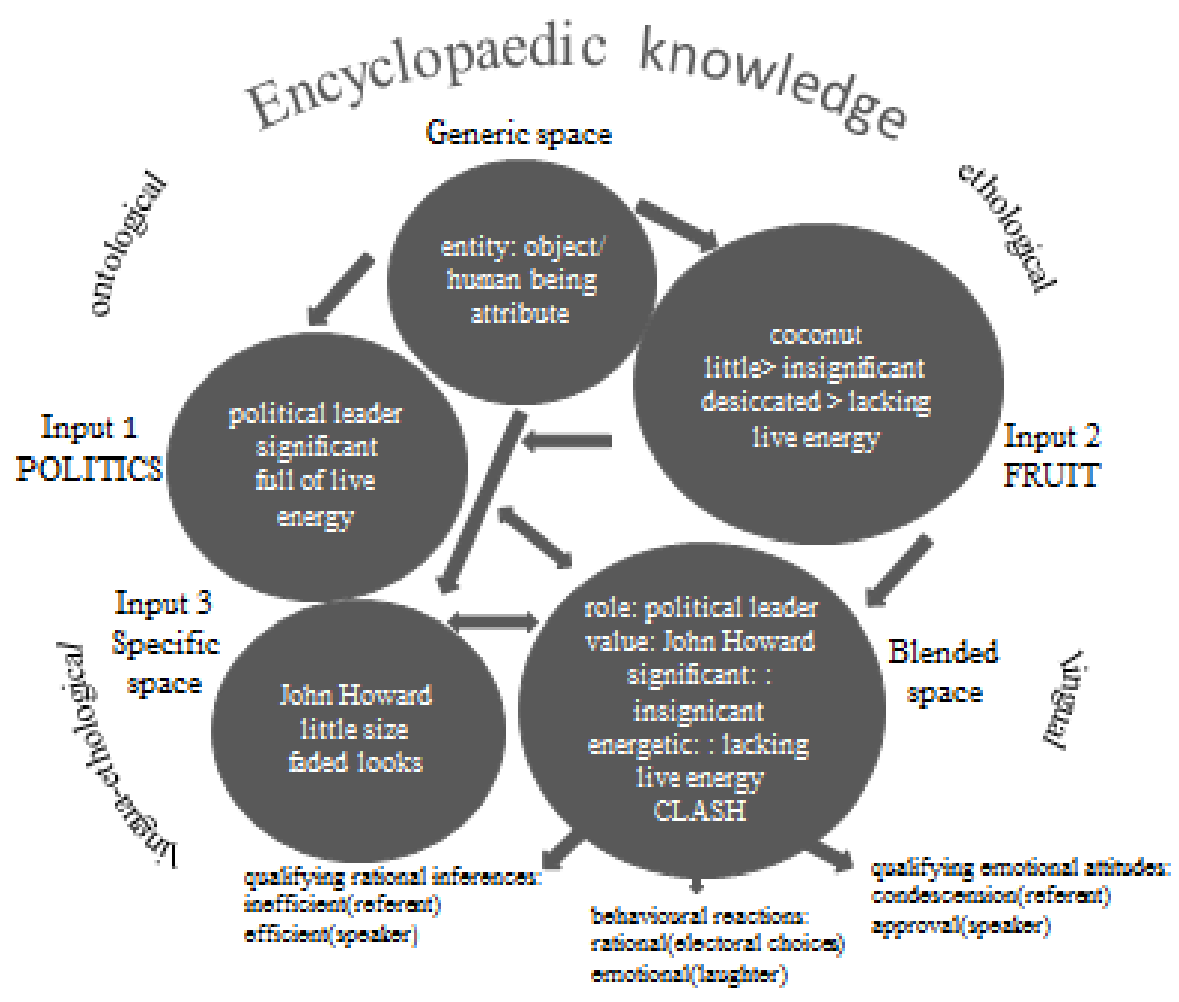

Figure 2. COCONUT blend.

The first input space (in terms of conceptual metaphor, it represents source domain) is structured by the frame POLITICS. In this frame, there is a role for POLITICAL LEADER, together with prototypical attributes associated with the ideal performer of this role. The prototypical attributes are selectively highlighted by the matching counterparts of the second input space (the target domain).

The second input space is structured by the frame FRUIT: There is a value COCONUT with the attributes ascribed to it ("little"/“desiccated"). The attributes imply that the coconut is not going to be tasty, so it is "unattractive" to the interpreter. The attributes of the FRUIT space are projected on the matching attributes of the POLITICS space on contrastive basis ("little”-“insignificant” :: (ideally) "significant”/“desiccated" — "having no live energy" :: (ideally) "full of live energy"). The prototypical attributes of an ideal political leader imply other attributes like "attractiveness" and "charisma".

The third "specific" space, which is also a source structure, contains the value JOHN HOWARD and all kinds of attributes associated with him, specifically "little size" and "faded looks", as it is conventional knowledge for those interested in Australian politics that there really was something of a coconut in John Howard's appearance. The attributes are brought into focus of attention by metaphoric mappings with the first two input spaces.

The blended space contains the value JOHN HOWARD taken from the "specific" space, the attributes "little" and "desiccated" from the first input space and the prototypical attributes of an ideal political leader- "significant”, "full of live energy” from the second input space.

The structures from the input spaces, providing the prototypical qualities of an ideal political leader and those of a faded fruit, characteristic of John Howard in metaphoric sense, are incompatible ("little size" :: “significance”; “desiccation” :: “live energy”; “unattractiveness” :: “charisma”). 
This incompatibility triggers the process of backward projection which gives rise to a new structure-a negatively assessed small-sized individual John Howard who lacks significance and live energy to be efficient in the role of a political leader.

The obvious inference based on rational assessment of the attributes of the referent is that these attributes make him insignificant and unattractive (uncharismatic) for the voters. Re-evaluation of this information in the backward projection onto the "specific" space lets the interpreter take into account that there really is something of a coconut in John Howard's appearance. This specific knowledge makes Paul Keating's joke quite realistic and effective. The speaker proves efficient in choosing the precise realistic image of a little desiccated coconut highlighting the qualities of the referent clashing with prototypical qualities of an ideal political leader. The similarity highlighted by this vivid coconut image evokes approval of the speaker on the part of interpreters and some condescending feeling towards the referent. Thus, this precise metaphor allows the speaker to produce an effective political insult and remain within (lingua)ethological norms so there are no constrains for the interpreters to react to the insult with laughter.

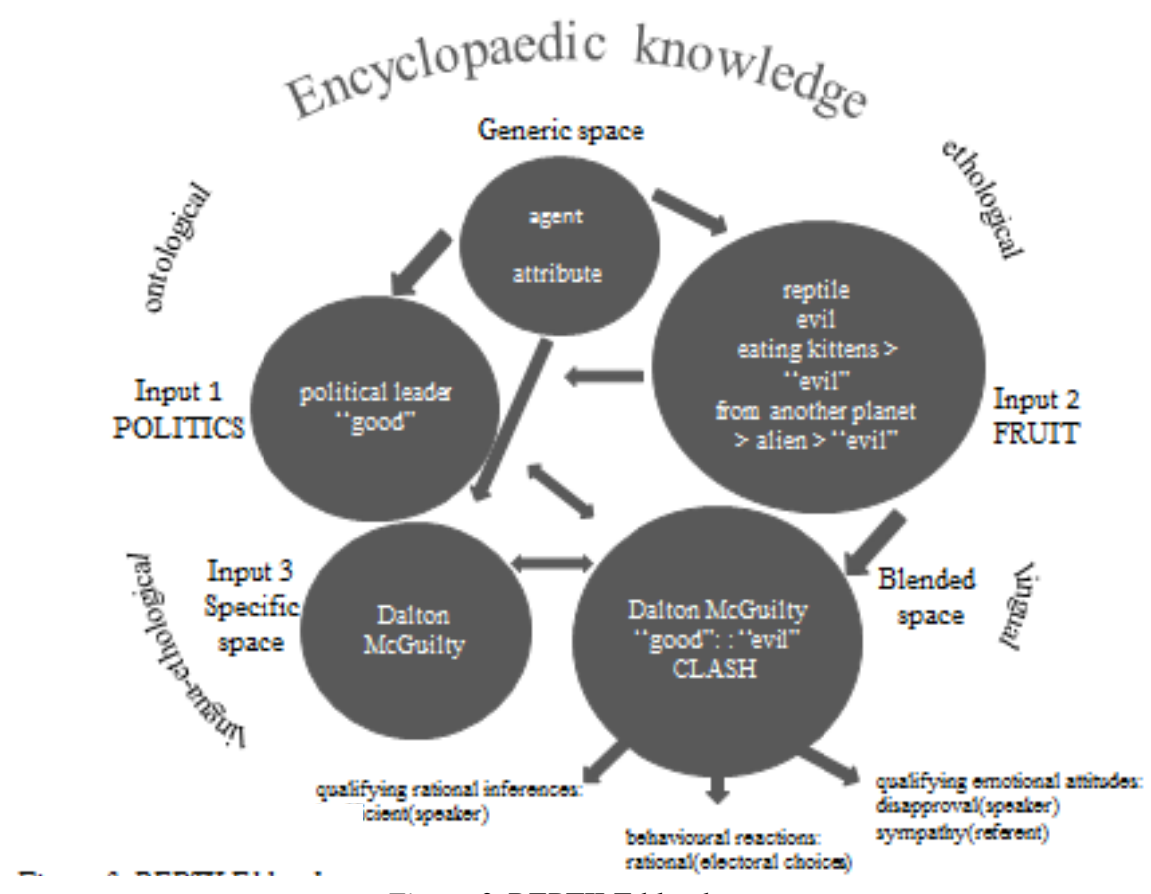

Figure 3. REPTILE blend.

The reptile metaphor represented in Figure 3 is also based on a multiple-scope network.

The generic space contains schematic information relating to AGENTS, UNDERGOERS, and their ATTRIBUTES which motivates matching operations and thus cross-space connections between the inputs.

The first input space (source domain) is structured by the frame POLITICS. In this frame, there is a role for POLITICAL LEADER, together with prototypical attributes associated with this role, highlighted by the attributes of the second input space.

The second (target) input space is structured by the frame REPTILES: There is a role REPTILE with the attributes ascribed to it ("evil”/“eating kittens"/“from another planet”). Actually, it seems difficult for the interpreter to induce the right schema for the interpretation of the construction an evil reptilian kitten-eater from another planet since the referent here is defined as a reptilian kitten-eater. The category of reptilian 
kitten-eaters is rather vague: It is hardly possible to associate a typical member of this category-a turtle, crocodilian, snake, or lizard—with such a genetic/intrinsic/characteristic (Langacker, 1987, p. 159) attribute as "eating kittens"; so it is easier for the interpreter to think of the referent as a reptile that among other things can eat kittens (the attribute being specific/non-intrinsic/non-characteristic).

The problem is that the attributes set by this input space are so vague ("evil", "kitten-eating" = "evil" since eating pet violates ethic norms of social behavior, "from another planet”- “alien” = stereotypically "evil”), that it is difficult for the interpreter to match them with prototypic attributes of an ideal political leader on metaphoric basis.

The third "specific" space, which is also a source structure, contains the value DALTON MCGUINTY and all kinds of attributes associated with him by Canadians. But it is not clear which attributes are meant to be brought into focus of attention by metaphoric mappings with the first (target) input space.

The blended space contains the value DALTON MCGUINTY from the specific space, the attribute "evil” from the first input space and some abstract attributes from the second input space characterizing an ideal politician. The abstract negative attribute "evil" is incompatible with the prototypical attributes of an ideal political leader, which are evaluated in terms of "good".

Re-evaluation of this information against the background of ontological and (lingua)ethological knowledge gives rise to the rational inference about inefficiency of the speaker in choosing the image which fails to highlight specific qualities of the referent incompatible with the role of a political leader. The choice of the wrong metaphoric image does not let the interpreter switch to the joking mode. In the serious mode of communication the speaker is considered a violator of lingua-ethological norms since the image of a kitten-eating reptilian from another planet is not only unrealistic, but also rather rude. The speaker's failure to choose the right image also results in the negative emotional attitude to him and sympathy for the referent on the part of the interpreters. Behavioral inferences in this case led to a political sandal—-the kitten eater occupied the premier's office while the Ontario Tory had to seek a new boss.

\section{Conclusion}

Summing up, appreciating a metaphoric insult involves: (1) ontological knowledge-effective insults highlight specific features of the referent incompatible with being a political leader; (2) ethological knowledge —effective insults do not violate ethic norms, avoiding vulnerable social or personal issues; (3) lingua-ethological knowledge - they do not violate norms of communicative behavior, avoiding direct verbal aggression; and (4) lingual knowledge - they do not violate language norms.

These results also apply to political insults expressed by simile, metonymy, oxymoron, hyperbole, and meiosis.

\section{References}

Attardo, S., \& Raskin, V. (1991). Script theory revis(it)ed: Joke similarity and joke representation model. Humour, 4, 3-4, 293-347.

Evans, V., \& Green, M. (2006). Cognitive linguistics: An introduction. Edinburgh: Edinburgh University Press.

Fauconnier, G., \& Turner, M. (2002). The way we think: Conceptual blending and the mind's hidden complexities. New York: Basic Books.

Koestler, A. (1964). The act of creation. New York: Macmillan.

Langacker, R. (1987). Foundations of cognitive grammar (Vol. I). Stanford, CA: Stanford University Press.

Minsky, M. (1980). Jokes and the logic of the cognitive unconscious. Cambridge, Mass: Artificial Intelligence Lab. 